\title{
Büyük ve Orta Boy İşletmeler İçin Finansal Raporlama Standardı İle İlgili Akademisyenlerin Farkındalıkları Hakkında Araştırma1
}

\author{
DOI: 10.26466/opus.583677 \\ * \\ Murat Serçemeli *- Muammer Paça** \\ * Dr. Öğr. Üyesi, Giresun Üniversitesi, İ.̇̇.B.F / Giresun / Türkiye \\ E-Posta: muratsercemeli@gmail.com \\ ORCID: $\underline{0000-0002-0718-2236}$ \\ ** Giresun Üniversitesi, Sosyal Bilimler Enstitüsü, Giresun/ Türkiye \\ E-Posta: $\underline{\text { muammerpaca@gmail.com }}$ \\ ORCID: $\underline{0000-0001-5072-6107}$
}

Öz

Muhasebe ve finans alanındaki gelişmelere bağhl olarak Türkiye'de finansal raporlama sisteminde değişimler yaşanmaktadır. Bu değiş̧imler ile birlikte yeni çıkan raporlama sistemleri muhasebe meslek mensupları ve muhasebe finans alanındaki akademisyenleri etkilemektedir. Kamu Gözetimi Kurumu tarafindan daha önce uluslararası finansal raporlama sistemine uyum sağlanmak için TFRS çıkarılmış daha sonra 2018 yılında BOBİ FRS yayınlanmıştır. Bu çalışmada, Kamu Gözetimi Kurumu tarafindan yayımlanan ve 1 Ocak 2018'den itibaren uygulanacak olan Büyük ve Orta Boy Işsetmeler Iç̧in Finansal Raporlama Standardı'na akademisyenlerin farkındalı̆̆ıı ölçmek ve akademisyenlerin farkındalıkları arasında farklılık olup olmadığının belirlenmesi amaçlanmıştır. Bu amaçla muhasebe finans alanında çalışan akademisyenlere anket çalışması yapılmıştır. Çalışma sonuçlarına göre akademisyenlerin BOBI FRS'nin, TMS/TFRS'lerin daha net anlaşılması ve doğru kullanılmalarına katkı sağlayacağını, iş dünyasının ihtiyaçları için gerekli olduğuna inandıkları ve BOBI FRS'ye göre hazırlanan finansal tabloların ülkede tek tip finansal tablo uygulamaların yaygınlaştıracağııı düşündükleri görülmüştür. Ayrıca akademisyenlerin çalıştıları bölgeler, TMS/TFRS ile ilgili ders vermeleri ile BOBİ FRS farkındalıkları arasında anlamlı farklılık olduğu saptanmıştır.

Anahtar Kelimeler: Büyük ve Orta Boy İşletmeler İçin Finansal Raporlama Standardı, Finansal Raporlama, TMS/TFRS

\footnotetext{
${ }^{1}$ Bu makale, Osmaniye Korkut Ata Üniversitesi tarafından düzenlenen, 18. Uluslararası İsletmecilik Kongresinde sunulan bildirinin geliştirilmiş halidir.
} 


\title{
A Research on Academicians' Awareness of The Financial Reporting Standard for Large and Medium-Sized Businesses
}

\begin{abstract}
Depending on developments in the fields of accounting and finance changes in the financial reporting system in Turkey is experiencing. With these changes, new reporting systems affect academicians in accounting and accounting finance. Previously issued by the Public Oversight Authority (TFRS) in order to ensure compliance with the international financial reporting system, then in 2018, the BOB FRS was published. The purpose of this study is measure the awareness of the academicians about to be implemented from 1 January 2018, the Financial Reporting Standard for Large and Medium Businesses published by the Public Oversight Agency and to determine whether there is any difference between the academicians' awareness. For this purpose, a survey was conducted among the academicians working in the field of accounting and finance. According to the results of the study, it was seen the academicians believes that BOBI FRS will contribute to a better understanding and correct use of the TMS I TFRS, it is necessary for the needs the business world and that the financial statements prepared according to $B O B I F R S$ will spread the uniform financial statements in the country. In addition, it was determined that there was a significant difference BOBI FRS awareness between academicians' working regions and giving lessons about TMS / TFRS.
\end{abstract}

Keywords Financial Reporting Standard for Large and Medium-Sized Enterprises, Financial Reporting, TMS/TFRS. 


\section{Giriş}

Dünya ekonomilerindeki hılı gelişim ve küreselleşme gibi etkiler ülkeler arasındaki sınırları kaldırmış, birbirleri arasındaki ticaret ve yatırımların kapsamını son derece geliştirmiştir. Artık bir yatırımcı, sadece kendi ülkesine değil dünyanın farklı ülkelerine bakarak, farklı sahalar keşfederek, farklı yatırımlar yapabilmeyi istemektedir.

Uluslararası ticaret ve rekabetin artması, uluslararası anlaşmaların yapılması ve teknolojinin hızla gelişmesi küreselleşmeyi başlatmış ve son yıllarda küreselleşmenin etkisi giderek artmıştır. Küreselleşmenin etkisi tüm alanları etkilediği gibi ekonomi alanını da etkilemiş ve değiştirmiştir. Ekonomi alanındaki küreselleşmenin etkisiyle ortaya çıkan bu değişim muhasebe alanında da değişimleri zorunlu kılmıştır. Her ülke kendine uygun farklı bir muhasebe sistemi kullanırken artık ortak bir muhasebe sistemine geçilmesi gerekliliği doğmuştur (Güneş vd., 2012, s.57).

İşletmelerle ortaklık kurmak, hisse senetlerine yatırım yapmak isteyen yatırımcılar ile kredi veren kurumlar için en mühim kaynak, o şirketin finansal tablolarıdır. Farklı ülkelerde faaliyet gösteren şirketlerin, kendine has muhasebe ve raporlama sisteminin oluşu, bu şirketler arasında şeffaf ve etkin bir şekilde karşılaştırma ve analiz yapmayı oldukça güçleştirmektedir. Bu güçlük tüm ülkelerde ortak bir muhasebe ve finansal raporlamanın yapilabilmesiyle giderilebilecektir.

Artık sınırları aşan faaliyetlerde bulunan işletmelerin artması, piyasa gelişmeleri, sermaye hareketleri ortak bir finansal raporlama sisteminin oluşmasını da hızlandırmıştır. Yatırımcılar uluslararası yatırımlar yapmakta ve yatırım konusunda sınır tanımamaktadır. Yatırım yapacakları ülkelerin ve işletmelerin finansal durumlarını anlamak, birbirleri ile karşılaştırmak için ortak bir finansal raporlamaya ihtiyaç duymaktadır. Her ülke kendine özgü raporlama sistemi vardır ama bunları birbirleriyle karşılaştırmak zordur çünkü ülkelerin farklı mevzuatları ve uygulamaları vardır. Küreselleşme hareketinin etkisiyle muhasebe ve finansal raporlama işlemlerini standartlaşma yoluna gidilmiş ve ortak bir muhasebe dili oluşturulmak istenmiştir (Kocamaz, 2012, s.106). Böylece ülkeler arasındaki farklılıklar azaltılmış veya ortadan kaldırılmış, finansal durum hakkında kolay karşılaştırılabilen, kolay anlaşılan bilgiler elde edilmeye çalışılmıştır. 
Ortaya çıkan bu ihtiyacı karşılamak için Uluslararası Muhasebe Standartları Komitesi (IASC) tarafından "Uluslararası Muhasebe Standartları" hazırlanmış dünya ülkelerinin onayına sunulmuştur. Türkiye'de değişen dünyaya ayak uydurmak için bu çalışmalara katılma kararı almış ve bu belirlenen standartlara geçmeye başlamıştır (Kaya ve Dinç, 2007:343-344). Türkiye' de bu çalışmaları Kamu Gözetim Kurumu (KGK) üstlenmiş ve Türkiye Muhasebe Standartları (TMS) ve Türkiye Finansal Raporlama Standartlarının (TFRS) geliştirilmesi, yayınlanması görevlerini yerine getirmeye çalışmaktadır.

KGK tarafından, "bağımsız denetime tabi olup TMS/TFRS uygulamayan işletmelerin münferit ve konsolide finansal tablolarını gerçeğe ve ihtiyaca uygun, karşılaştırılabilir bilgi sağlamasını için Büyük ve Orta Boy İşletmeler için Finansal Raporlama Standardı (BOBI FRS) yürürlüğe konulmuştur. BOBI FRS 29 Temmuz 2017 tarihinde 30138 sayılı mükerrer Resmî Gazete tarafindan yayımlanmış ve 1 Ocak 2018 tarihi ve sonrasında başlayan hesap dönemlerinde uygulanmak üzere yayımlandığı tarihte yürürlüğe girmiştir" (30138, Resmî Gazete).

Çalışmada öncelikle BOBİ FRS ile ilgili genel bilgiler ve literatür araştırmasına yer verilecek ardından akademisyenlerin BOBİ FRS farkındalıkları ile ilgili araştırma sonuçlarına yer verilecektir.

\section{BOBİ FRS ve Literatür Araştırması}

BOBİ FRS'yi uygulayacak işletmelerin tanımı şu şeklide yapılmıştır. "Aktif toplamı 75 milyon ve üstü Türk Lirası, yıllık net satış hasılatı 150 milyon ve üstü Türk Lirası, ortalama çalışan sayısı 250 ve üstü olan işletmeler olarak tanımlanmıştır. Bu üç ölçütten en az ikisinin eşik değerlerini varsa bağlı ortaklıklarıyla birlikte, art arda iki raporlama döneminde aşan işletmeler müteakip raporlama döneminde büyük işletme olarak değerlendirilir" (30138, Resmî Gazete). 29 Temmuz 2017 tarihinde yayımlanan 30138 sayılı mükerrer Resmî Gazete' deki BOBİ FRS tebliğinde büyük işletmeler kapsamını anlatan 6. maddenin, 2014 yılındaki bağımsız denetim kapsamına alınan şirketler tanımında kullanılan kriterler baz alınarak değerlendirilmiştir (Öztürk, 2017, s.597).

BOBİ FRS'nin genel yapısı ve özellikleri (KGK ,2017): 
- 27 bölümden oluşur, işletmelerin karşılarına çıkabilecek tüm muhasebe işlemlerine ilişkin muhasebe esaslarmı belirler, başka bir muhasebe ve finansal raporlama setine ihtiyaç olmadan finansal tabloların hazırlanmasinı sağlar".

- "Uluslararası muhasebe ve finansal raporlama uygulamalar, AB düzenlemeleri ile uyumludur, Kabul edilebilir bir finansal raporlamanin gerektirdiği tüm özellikleri taşır".

- "AB muhasebe direktiflerine uygun olarak, orta büyüklükteki işletmeler için maliyet esasl finansal raporlama, büyük işletmelere ise ilâve yükümlülükler getirmiştir".

- "Konular sade ve anlaşılır bir şekilde ele alınmıştır".

TMS/TFRS uygulamayan şirketler için Muhasebe Sistemi Uygulama Genel Tebliğleri (MSUGT) 41 sayılı kararınca uygulanacak ilave hususları göz önünde bulundurarak raporlama yapması gerekmektedir. TMS/TFRS ile MSUGT arasında farklar olduğundan bağımsız muhasebe denetiminde çifte standart ortaya çıkmıştır. BOBİ FRS ile Kamu Yararını İlgilendiren Kuruluşlar (KAYİK) dişında kalan ve bağımsız denetime tabi tüm şirketlerin denetiminde çifte standardı ortadan kaldıracaktır (Gençoğlu, 2017, s.2). Aynı zamanda uluslararası standardın uygulama alanının genişlemesi ve Uluslararası Finansal Raporlama Standartları'na (UFRS) yakın finansal raporların elde edilmesi amaçlanmıştır (Öztürk, 2017, s.596). BOBİ FRS gerçeğe ve finansal bilgi ihtiyacına uygun, karşılaştırılabilir finansal tablolar için KGK tarafından TMS/TFRS'ye göre sade bir dille hazırlamış, büyük ve orta ölçekli işletmelerin ihtiyacı olmayan bilgiler yerine temel konulara yer verilmiştir (Ataman ve Cavlak, 2017, s.156).

BOBİ FRS ile Avrupa Birliği (AB) direktiflerinde yer alan MSUGT'de yer almayan bazı muhasebe yaklaşımları bu set ile uygulanmaya başlayacaktır, yine AB direktifleri doğrultusunda yapılan TFRS ile BOBİ FRS arasında önemli ölçüde farklar bulunmaktadır. BOBİ FRS uluslararası kabul edilebilirliğinden çok bağımsız muhasebe denetiminin kabulü ve devamı için oluşturulmuş bir set olduğu eleştirisi söylenmektedir (Öztürk, 2017, s.613). 
Tablo 1. BOBİ FRS ile TMS/TFRS standartları karşılaştırması(Gençoğlu, 2017)

\begin{tabular}{l}
\hline BOBI FRS \\
"B1 Kavramsal Çerçeve ve Finansal Tablolar" \\
\hline "B2 Nakit Akış Tablosu" \\
\hline "B3 Muhasebe Politikaları, Tahminler ve Yan- \\
lışlıklar" \\
"B4 Raporlama Döneminden Sonraki Olaylar" \\
\hline "B5 Hasılat" \\
\hline "B6 Stoklar" \\
"B7 Tarımsal Faaliyetler" \\
"B8 Maden Kaynaklarının Aranması ve Değer- \\
lendirilmesi" \\
\hline
\end{tabular}
TMS/TFRS

"Finansal Raporlamaya İlişkin Kavramsal Çerçeve ile TMS 1 Finansal Tablolarm Sunuluşu" "TMS 7 Nakit Akış Tabloları"

"TMS 8 Muhasebe Politikalar, Muhasebe Tahminlerinde Dĕ̆işiklikler ve Hatalar"

"TMS 10 Raporlama Döneminden (Bilanço Tarihinden) Sonraki Olaylar"

"TMS 11 Inşaat Sözleşmeleri" ve

"TMS 18 Hasilat"

"TMS 2 Stoklar"

"TMS 41 Tarmsal Faaliyetler"

"TFRS 6 Maden Kaynaklarının Araştırılması ve Değerlendirilmesi"

"TMS 32 Finansal Araçlar: Sunum"

"B9 Finansal Araçlar ve Özkaynaklar"

"TMS 39 Finansal Araçlar: Muhasebeleştirme ve Ölçme"

"TFRS7 Finansal Araçlar: Açıklamalar" "TFRS 9 Finansal Araçlar"

"TMS 28 Işstiraklerdeki ve İş Ortaklıklarındaki Ya-

"B10 İştiraklerdeki Yatırımlar" tırimlar"

\begin{tabular}{|c|c|}
\hline "B11 Müşterek Girişimlerdeki Yatırımlar" & "TFRS 11 Müşterek Anlaşmalar" \\
\hline "B12 Maddi Duran Varliklar" & "TMS 16 Maddi Duran Varliklar" \\
\hline "B13 Yatırım Amaçlı Gayrimenkuller" & "TMS 40 Yatırım Amaçlı Gayrimenkuller" \\
\hline "B14 Maddi Olmayan Duran Varliklar" & "TMS 38 Maddi Olmayan Duran Varliklar" \\
\hline "B15 Kiralamalar" & "TMS 17 Kiralama İşlemleri" \\
\hline "B16 Devlet Teşvikleri" & $\begin{array}{l}\text { "TMS } 20 \text { Devlet Teşviklerinin Muhasebeleştiril- } \\
\text { mesi ve Devlet Yardımlarının Açıklaması" }\end{array}$ \\
\hline "B17 Borçlanma Maliyetleri" & "TMS 23 Borçlanma Maliyetleri" \\
\hline "B18 Varlıklarda Dĕger Düşüklüğ̈̈" & "TMS 36 Varlıklarda Değer Düşüklüğü" \\
\hline $\begin{array}{l}\text { "B19 Karşılıklar, Şarta Bă̆lı Yükümlülükler ve } \\
\text { Şarta Bağlı Varlıklar" }\end{array}$ & $\begin{array}{l}\text { "TMS } 37 \text { Karşılıklar, Koşullu Borçlar ve Koşullu } \\
\text { Varlıklar" }\end{array}$ \\
\hline "B20 Yabancı Para Çevrim İşlemleri" & "TMS 21 Kur Değişiminin Etkileri" \\
\hline "B21 İş Birleşmeleri" & "TFRS 3 İşletme Birleşmeleri" \\
\hline "B22 Konsolide Finansal Tablolar" & "TFRS 10 Konsolide Finansal Tablolar" \\
\hline "B23 Gelir Üzerinden Altnan Vergiler" & "TMS 12 Gelir Vergileri" \\
\hline "B24 Ara Dönem Finansal Raporlama" & "TMS 34 Ara Dönem Finansal Raporlama" \\
\hline $\begin{array}{l}\text { "B25 Yüksek Enflasyonlu Ekonomilerde Finan- } \\
\text { sal Raporlama" }\end{array}$ & $\begin{array}{l}\text { "TMS } 29 \text { Yüksek Enflasyonlu Ekonomilerde Finan- } \\
\text { sal Raporlama" }\end{array}$ \\
\hline "B26 Dipnotlar" & $\begin{array}{l}\text { "TMS } 1 \text { Finansal Tabloların Sunuluşu ve her stan- } \\
\text { dardın kendi içinde dipnotlarda yapılması gereken } \\
\text { açıklamaların neler olacağına yer verilmektedir." }\end{array}$ \\
\hline "B27 Geçiş Hükümleri” & $\begin{array}{l}\text { "TFRS } 1 \text { Türkiye Finansal Raporlama Standartla- } \\
\text { rinın Illk Uygulaması" }\end{array}$ \\
\hline
\end{tabular}


Öztürk (2017) tarafından yapılan çalışmada, Türkiye'de finansal raporlamanın gelişiminden bahsetmiş, BOBİ FRS'yi açıklamış, finansal varlıkların sınıflandırılması, ölçülmesi ve muhasebeleştirilmesini TFRS ve BOBİ FRS açısından karşılaştırmış ve uygulamalı sorular üzerinden açıklamış ve aradaki farkları anlatmıştır. BOBİ FRS' de kapsamlı gelir tablosu yerine kar veya zarar tablosu düzenlenmesi gerektiğini, tek düzen hesap planındaki hesapların BOBİ FRS'yi karşılamada yetersiz kaldığını belirtmiştir.

Gençoğlu (2017) tarafından yapılan çalışmada, TFRS ile BOBİ FRS'yi temel konularda karşılaştırmış, karşılaştırma sonucunda tam set standart seti ile BOBİ FRS'nin büyük ölçüde uyumlu olduğunu tespit etmiş, BOBİ FRS kapsamina alınmayan ve yapılan sadeleştirmelerle finansal durum tablolarında değişikliklere ve aradaki farklara değinmiştir. BOBİ FRS'nin daha sade daha anlaşılır bir standart getirdiğini, daha kolay uygulanabileceğini, vergi muhasebesi yerine bilgi muhasebesi anlayışının gelişeceğini, muhasebe eğitimi ve uygulamaların kolaylaşacağını söylemiştir.

Ataman ve Cavlak (2017) yaptıkları çalışmada uluslararası finansal raporlama sisteminin kullanılmasından ve Türkiye' deki finansal raporlamanın gelişiminden bahsetmiştir. BOBI FRS ile TFRS'yi karşılaştırarak, TFRS'de yer alıp BOBİ FRS'de yer almayan ve her ikisinde de yer alan standartlara ve aradaki farklara değinmiştir. Sonuç olarak muhasebe ve finansal raporlama alanında ilerleme kaydettiğimizi, küçük ölçekli işletmeler içinde uyumlu bir set hazırlanarak vergi odaklı muhasebeden kurtulmalarının ilerlemeyi hızlandıracağını ve Türkiye'nin ekonomisine değer katacağını söylemiştir.

Doğan (2017) çalışmasında BOBİFRS ile TMS/TFRS karşılaştırarak aralarındaki benzerlik ve farklar ortaya koymuştur. Karşılaştırma sonucunda BOBIFRS' de daha basit muhasebe ilkelerine yer verildiğini ve TFRS' de yer alan gerçeğe uygun değerle birlikte BOBİFRS' de maliyet bedeli esası benimsendiğini söylemiştir.

Şen ve Özbirecikli (2018) çalışmalarında BOBİFRS ile TFRS/TMS ve MSGUT/VUK karşılaştırmasını yaparak BOBİFRS ile birlikte muhasebe uygulamalarında bir değiş̧iklik olup olmadığını, muhasebe sistemine bir katkı sağlayıp sağlamadığını araştırmışlardır. Uluslararası muhasebe uygulamaları ve Avrupa Birliği uygulamaları ile uyumlu olduğunu, 
MSGUT' nin eksik olan taraflarını tamamlaması ve büyük ve orta büyüklükteki işletmelerin TFRS/TMS uygulamalarını daha kolay hale getirmesine yardımcı olacağını söylemiştir.

Sakarya ve diğerleri (2018) tarafından yapılan çalışmada Balıkesir ilindeki mali müşavirler ve muhasebe meslek mensupları üzerinde bir anket çalışması yaparak meslek mensuplarının farkındalığını ölçmeye çalışmışlardır. Anket sonucunda BOBİFRS ile ilgili kursa gidenlerin gitmeyenlere göre daha yüksek bilinirlik ve farkındalık düzeyine sahip olduğu görülmüştür ayrıca standartlara ait açıklamaların net ve anlaşılır olması uygulama kolaylığı sağlayacağı söylenmiştir.

Gökçen ve arkadaşları (2018) çalışmalarında TMS/TFRS ile BOBİFRS' ye göre muhasebe kayıtlarını karşılaştırarak aralarındaki farklara değinmişlerdir. Genel olarak aradaki farklar BOBİFRS ilk muhasebeleştirme ve sonraki ölçümlerde tarihi maliyetle ilgili ölçüm esası sunması, BOBİFRS' nin muhasebeleştirme işlemlerinin daha az yoğunlukta, pratik ve kolay olmasından kaynaklandığını belirtmiştir.

Mozeikçi ve Şahinoğlu (2018) BOBİFRS' nin getirdiği yenilikler ve değişimleri meslek mensupları tarafından nasıl algılandığını araştırmışlardır. Kırklareli ilinde muhasebe meslek mensupları arasında anket çalışması yapılmış ve ankete katılanlar ülkemizde kaliteli finansal raporlama açısından önemli olduğunu, finansal tablo analiz ve yorumlarını kolaylaştıracağını, tablo sayısının artmasıyla iş yükünün artacağını, finansal bilginin niteliğinin artacağını ve güvenilir bilgi elde edilmesi açısından önemli olduğunu düşünmektedirler.

Öztürk ve Çarıkçı (2018) çalışmalarında BOBİFRS' nin muhasebe meslek mensuplarındaki algı düzeyini araştırmış ve Batı Akdeniz Bölgesi'ndeki meslek mensupları ile yüz yüze görüşerek anket çalışması yapışlardır. Yapılan faktör analiziz sonucunda meslek mensuplarının beklenti algılarının çok yüksek olduğu geleceği ile ilgili olumlu düşünceler içinde oldukları bunun yanı sıra eğitim beklentisi düşük olduğu eğitimlerin yetersiz olduğunu düşünmektedirler. Genç ve mesleğe yeni başlayan meslek mensuplarının genç olmayan tecrübeli meslek mensuplarına göre beklenti farklılığı olduğu, BOBİFRS mükellefine sahip olanlar ile olmayanlar arsında farkındalık ve kolaylık bakımından farklılık olduğu ve BOBİFRS ile ilgili eğitim alanlarla almayanlar arasında farkındalık, eğitim ve kolaylık boyutlarında farklılıklar olduğu belirlenmiştir. 
Ataman ve arkadaşları (2019) çalışmalarında kâr veya zarar tablosu ve finansal durum tablosunu BOBIFRS' ye göre uyarlamış ve bunun sonucunda ortaya çıkacak değişiklikleri finansal rasyolar ile analiz etmeye çalışmışlardır. BOBİFRS düzenleme sonucundaki finansal oranlar ile düzenleme öncesindeki finansal oranların arasında farklar bulunmuştur. Buna göre geleneksel olarak yapılan finansal oranların yeni çıkan finansal raporlama standartlarına göre yeniden güncellenmesi gerektiğini vurgulamiştır.

Bu çalışmanın akademisyenlerin farkındalıkları ve bakış açılarını vermesi bakımından literatüre katkı sağlayacağı düşünülmektedir.

\section{Akademisyenlerin BOBİ FRS Farkındalıklarına Yönelik Araştırma}

\section{Araştırmanın Amacı}

Araştırmanın amacı; üniversitelerin ilgili fakültelerinde muhasebe-finans alanında eğitim veren akademisyenlerin BOBİ FRS'lere bakış açıları ve farkındalık düzeylerini tespit etmektir. Bu bağlamda akademisyenlerin; "Cinsiyet", "Yaş", "Mesleki Tecrübe", "Çalıştığı Bölge", "Haftalık Ders Saati", "Unvan", "TMS/TFRS ile ilgili ders verme durumları" gibi değişkenler açısından bakış açıları ve farkındalıkları arasında farklılık olup olmadığı araştırılmıştır.

\section{Araştırmanın Kapsamı ve Yöntemi}

Araştırma muhasebe ve finans alanında çalışan akademisyenleri kapsamaktadır. İlgili akademisyenlere ulaşmak için üniversitelerin resmi internet sitelerinden mail adresleri toplanmış ve elektronik ortamda hazırlanan anket formu mail yoluyla gönderilmiştir ve bunlardan 118 akademisyen ankete dönüş yapmıştır.

Anket formlarının tamamı analize dâhil edilmiş ve anket sonuçlarının analizinde SPSS 17,0 bilgisayar programından faydalanılmıştır. Anket formu toplam olarak 19 adet sorudan oluşmaktadır. Bu sorulardan 7 tanesi demografik bilgi için geriye kalan 12 tanesi ise akademisyenlerin BOBİ FRS hakkındaki farkındalık düzeylerini tespit etmek için 5'li likert modeli kullanılarak oluşturulmuştur. Anket soruları oluştururken Yılmaz 
vd. (2014) ve Gençoğlu (2017) çalışmalarından faydalanılmıştır. Araştırmanın amaçları çerçevesinde aşağıda belirtilen alternatif hipotezler belirlenmiş ve bu hipotezler istatistiksel analizler sonucunda test edilmiştir:

- H1: Akademisyenlerin cinsiyetleri ile BOBİ FRS farkındalıkları arasinda anlamlı bir fark vardır.

- $\quad \mathbf{H}_{2}$ : Akademisyenlerin yaşları ile BOBİ FRS farkındalıkları arasında anlamlı bir fark vardır.

- $\quad \mathbf{H}_{3}$ : Akademisyenlerin mesleki tecrübeleri ile BOBI FRS farkındalıkları arasında anlamlı bir fark vardır.

- $\quad \mathbf{H}_{4}$ : Akademisyenlerin çalıştıkları bölgeler ile BOBİ FRS farkındalıkları arasında anlamlı bir fark vardır.

- H5: Akademisyenlerin ders saatleri ile BOBİ FRS farkındalıkları arasinda anlamlı bir fark vardır.

- H6: Akademisyenlerin unvanları ile BOBİ FRS farkındalıkları arasında anlamlı bir fark vardır.

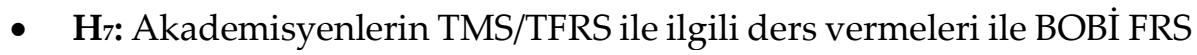
farkındalıkları arasında anlamlı bir fark vardır.

\section{Araştırmanın Bulguları ve Analizi}

Çalışmanın bu bölümünde yapılan araştırmadan elde edilen sonuçlar analiz edilmektedir. Ankete katılan akademisyenlerin demografik bilgileri ile verdikleri dersler ile ilgili bilgiler Tablo 2' de görülmektedir.

Ankete katılan akademisyenlerin özellikleri arasında en fazla öne çıan değerler; \%68,6'sı erkek, \%46,6'sı 31-40 yaş aralığında, \%22,9'u İç Anadolu Bölgesi'nden akademisyen katılmış, unvan olarak \%36,4'ü yardımcı doçenttir. Ankete katılan akademisyenlerin \%58,5'i ise TMS/TFRS ile ilgili şimdiye kadar herhangi bir ders vermemiştir. 
Tablo 2. Demografik Özellikler

\begin{tabular}{llcc}
\hline & & Frekans & (\%)Yüzde \\
\hline Cinsiyet & Erkek & 81 & 68,6 \\
& Kadın & 37 & 31,4 \\
\hline Yaş & 30 ve altı & 20 & 16,9 \\
& $31-40$ & 55 & 46,6 \\
& $41-50$ & 21 & 17,8 \\
& 51 ve üstü & 22 & 18,6 \\
\hline Mesleki Tecrübe & $1-10$ & 54 & 45,8 \\
& $11-20$ & 33 & 28,0 \\
& $21-30$ & 22 & 18,6 \\
& 31 ve üstü & 9 & 7,6 \\
\hline Çalıştığı Bölge & Marmara & 25 & 21,2 \\
& Ege & 5 & 4,2 \\
& Akdeniz & 14 & 11,9 \\
& İç Anadolu & 27 & 22,9 \\
& Karadeniz & 22 & 18,6 \\
& Doğu Anadolu & 16 & 13,6 \\
& GD Anadolu & 9 & 7,6 \\
\hline Haftalık Ders Saati & 10 ve altı & 44 & 37,3 \\
& $11-20$ & 34 & 28,8 \\
& $21-30$ & 29 & 24,6 \\
& 30 ve üstü & 11 & 9,3 \\
\hline Unvan & Öğr. Gör. & 3 & 2,5 \\
& Araş. Gör. & 32 & 27,1 \\
TMS/TFRS ile ilgili şimdiye kadar verdiniz mi? & Dir. Öğr. Üyesi & 43 & 36,4 \\
& Doç. & 24 & 20,3 \\
& Evet. & 16 & 13,6 \\
\hline
\end{tabular}

Anket sorularına verilen yanıtlar arasında en çok “BOBİ FRS'nin iş dünyasının ihtiyaçları için gerekli olduğuna inanyorum" ve "BOBİ FRS, TMS/TFRS'lerin daha net anlaşılması ve doğru kullanılmalarına da katkı sağlayacaktır" ile "BOBİ FRS ülkemizdeki vergi için muhasebe anlayışından, bilgi için muhasebe anlayışa geçiş için önemli bir aşama olacaktır" ifadeleri öne çıkmıştır. Bu da TMS ve TFRS'lerin henüz yeterince anlaşılmadığı ve bu yönde çalışmalar yapılması gerektiği ve iş dünyasının bu yönde gelişmelere ihtiyaç duyduğunu göstermektedir. 
Tablo 3. ВOBİ FRS İfadeler Frekans Tablosu

\begin{tabular}{|c|c|c|c|c|c|c|c|c|}
\hline \multirow{2}{*}{ İFADELER } & \multicolumn{2}{|c|}{ Katılmıyorum } & \multicolumn{2}{|c|}{ Kararsızım } & \multicolumn{2}{|c|}{ Katılıyorum } & \multirow[t]{2}{*}{ Ort. } & \multirow{2}{*}{$\begin{array}{l}\text { Std. } \\
\text { Sapma }\end{array}$} \\
\hline & F & $\%$ & F & $\%$ & $\mathbf{F}$ & $\%$ & & \\
\hline $\begin{array}{l}\text { BOBI FRS konuları ile ilgili } \\
\text { araştırma yaptım ve bilgi sa- } \\
\text { hibiyim. }\end{array}$ & 41 & 34,7 & 17 & 14,4 & 60 & 50,8 & 3,14 & 1,32 \\
\hline $\begin{array}{l}\text { Mevcut muhasebe bilgim } \begin{array}{r}\text { BOBİ } \\
\text { FRS'leri uygulayabilmem } \\
\text { yeterlidin }\end{array} \\
\end{array}$ & 34 & 28,8 & 24 & 20,3 & 60 & 50,8 & 3,31 & 1,26 \\
\hline $\begin{array}{l}\text { BOBI FRS, TMS/TFRS'nin sadece } \\
\text { kısaltılmış hali değildir ve ara- } \\
\text { larında başka farklar da vardır. }\end{array}$ & 13 & 11 & 27 & 22,9 & 78 & 66,1 & 3,75 & 1,06 \\
\hline $\begin{array}{l}\text { BOBİ FRS bağımsız denetime tabi } \\
\text { tüm şirketler için çifte standart uy- } \\
\text { gulamasını ortadan kaldıracaktır. }\end{array}$ & 18 & 15,3 & 51 & 43,2 & 49 & 41,6 & 3,26 & 1,01 \\
\hline $\begin{array}{l}\text { BOBI FRS'de genel olarak maliyet } \\
\text { esaslı bir finansal raporlama ön- } \\
\text { görülmüştür. }\end{array}$ & 24 & 20,4 & 56 & 47,5 & 38 & 32,2 & 3,17 & 0,98 \\
\hline $\begin{array}{l}\text { BOBİ FRS ile TMS'de kullanılan fi- } \\
\text { nansal durum tablosu, kâr zarar } \\
\text { tablosu ve özkaynak değişim } \\
\text { tablosu formatlarında farklılıklar } \\
\text { bulunmaktadır. }\end{array}$ & 21 & 17,8 & 44 & 37,3 & 53 & 45 & 3,36 & 1,08 \\
\hline $\begin{array}{l}\text { BOBİ FRS, TMS/TFRS uygulamaları } \\
\text { karışı olduğundan, daha sade } \\
\text { yapısıyla daha yararlı ve kolay } \\
\text { olacaktır. }\end{array}$ & 9 & 7,6 & 33 & 28,0 & 76 & 64,4 & 3,73 & 0,99 \\
\hline $\begin{array}{l}\text { BOBİ FRS ile gerçek faaliyet rapor- } \\
\text { larıyla, gerçek durum tespiti, plan- } \\
\text { lama ve denetim için kullanılabilir } \\
\text { bilgiler üretmek mümkün hale } \\
\text { gelecektir. }\end{array}$ & 13 & 11 & 37 & 31,4 & 68 & 57,7 & 3,53 & 0,90 \\
\hline $\begin{array}{l}\text { BOBİ FRS ülkemizdeki vergi için } \\
\text { muhasebe anlayışından, bilgi için } \\
\text { muhasebe anlayışa geçiş için } \\
\text { önemli bir aşama olacaktır. }\end{array}$ & 13 & 11 & 30 & 25,4 & 75 & 63,6 & 3,76 & 1,02 \\
\hline 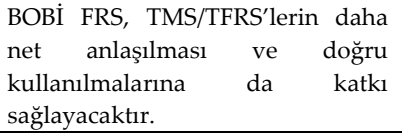 & 10 & 8,4 & 25 & 21,2 & 83 & 70,3 & 3,80 & 0,92 \\
\hline $\begin{array}{l}\text { BOBI FRS'nin iş dünyasının ih- } \\
\text { tiyaçları için gerekli olduğuna } \\
\text { inanıyorum. }\end{array}$ & 6 & 5 & 33 & 28,0 & 79 & 67 & 3,86 & 0,93 \\
\hline $\begin{array}{l}\text { BOBI FRS'ye göre hazırlanan fi- } \\
\text { nansal tablolar, hem daha ayrıntılı } \\
\text { bir rehber olacak, hem de ülkede } \\
\text { tek tip finansal tablo uygulama- } \\
\text { larını yaygınlaştıracaktır }\end{array}$ & 10 & 8,5 & 35 & 29,7 & 73 & 61,9 & 3,75 & 0,99 \\
\hline
\end{tabular}


Akademisyenlerin farkındalıklarını ölçmek için yapılan anketin güvenilirliği için Cronbach's Alpha analizi kullanılmıştır. Anket Cronbach's Alpha katsayısı 0,86 bulunmuştur. Sosyal bilim araştırmalarında \%70 ve üzeri olan güvenilirlik katsayısı, güvenilirlik düzeyinin geçerli olması için yeterlidir (Bayram, 2017, s.194). Gözlem sayısı 29'dan az olduğunda Shapiro-Wilk testi, gözlem sayısı 29 ve daha büyük olduğunda ise Kolmogorov-Smirnov testi kullanılabilir. (Kalaycı, 2010, s.10). Veri sayımız 118 olduğu için Kolmogorov-Smirnov testi kullanılmıştır. Verilerin normallik analizi yapıldığında \%5 anlamlılık düzeyinde Sig. Değeri $(0,200) \% 5$ ten büyük olduğu için verilerin normal dağıldığı söylenir.

\section{H1: Akademisyenlerin Cinsiyeti ile BOBİ FRS Hakkındaki} Farkındalıkları Arasında Anlamlı Bir Fark Vardır

$\mathrm{H}_{1}$ hipotezinin sınanması konusunda, cinsiyet açısından BOBİ FRS hakkındaki farkındalık düzeyleri gruplar arasındaki farklılıklar, "bağımsız gruplar $\mathrm{t}$ testi" ile ortaya konulmaya çalışılmıştır. Sınama sonuçları Tablo 4'de verildiği gibidir.

Tablo 4. Cinsiyet - Farkındalık Durumlarına Yönelik t testi Özet Tablosu

\begin{tabular}{lllll}
\hline Cinsiyet & $\mathbf{N}$ & Ortalama & $\mathbf{t}$ & $\mathbf{P}$ \\
\hline Erkek & 81 & 3,49 & \multirow{2}{*}{1,126} & \multirow{2}{*}{0,263} \\
Kadın & 37 & 3,64 & & \\
\hline
\end{tabular}

Yapılan t testi test sonucu \%5 anlamlılık düzeyi $(0,263>0,05)$ için $\mathrm{H}_{1}$ hipotezi reddedilmiştir. Bunun göre akademisyenlerin cinsiyeti ve BOBİ FRS farkındalığı arasında anlamlı bir fark yoktur.

\section{H2: Akademisyenlerin Yaşları ile BOBİ FRS Farkındalıkları Arasında An- lamlı Bir Fark Vardır}

$\mathrm{H}_{2}$ hipotezinin sınanması konusunda, yaş açısından BOBİ FRS hakkındaki farkındalık düzeyleri gruplar arasındaki farklılıklar, "varyans testi" ile ortaya konulmaya çalışılmıştır. Sınama sonuçları Tablo 5'de verildiği gibidir. 
Tablo 5. Yaş - Farkındalık Durumlarına Yönelik Varyans Testi Özet Tablosu

\begin{tabular}{|c|c|c|c|c|}
\hline Yaş & $\mathbf{N}$ & Ortalama & $\mathbf{F}$ & $\mathbf{P}$ \\
\hline 30 ve alt1 & 20 & 3,51 & \multirow{4}{*}{1,201} & \multirow{4}{*}{0,313} \\
\hline $31-40$ & 55 & 3,46 & & \\
\hline $41-50$ & 21 & 3,77 & & \\
\hline 51 ve üstü & 22 & 3,52 & & \\
\hline
\end{tabular}

Yapılan varyans testi test sonucu $\% 5$ anlamlılık düzeyi $(0,313>0,05)$ için $\mathrm{H}_{2}$ hipotezi reddedilmiştir. Bunun göre akademisyenlerin yaşları ve BOBİ FRS farkındalığı arasında anlamlı bir fark yoktur.

H3: Akademisyenlerin Mesleki Tecrübeleri ile BOBİ FRS Farkındalıklarn Arasında Anlamlı Bir Fark Vardır

$\mathrm{H}_{3}$ hipotezinin sınanması konusunda, mesleki tecrübe açısından BOBİ FRS hakkındaki farkındalık düzeyleri gruplar arasındaki farklılıklar, "varyans testi" ile ortaya konulmaya çalışılmıştır. Sınama sonuçları Tablo 6 'da verildiği gibidir.

Tablo 6. Mesleki Tecrübe - Farkındalık Durumlarna Yönelik Varyans Testi Özet Tablosu

\begin{tabular}{lllll}
\hline $\begin{array}{l}\text { Mesleki } \\
\text { Tecrübe (Y1) }\end{array}$ & $\mathbf{N}$ & Ortalama & F & P \\
\cline { 1 - 2 } $1-10$ & 54 & 3,44 & \\
\cline { 1 - 2 } $11-20$ & 33 & 3,59 & 0 \\
\cline { 1 - 2 } $21-30$ & 22 & 3,72 & 0,369 \\
\hline 31 ve üstü & 9 & 3,45 & \\
\hline
\end{tabular}

Yapılan varyans testi test sonucu \%5 anlamlılık düzeyi $(0,369>0,05)$ için $\mathrm{H}_{3}$ hipotezi reddedilmiştir. Bunun göre akademisyenlerin yaşları ve BOBİ FRS farkındalığı arasında anlamlı bir fark yoktur.

\section{$\mathrm{H}_{4}$ : Akademisyenlerin Çalıştıkları Bölgeler ile BOBİ FRS Farkındalık- ları Arasında Anlamlı Bir Fark Vardır}

$\mathrm{H}_{4}$ hipotezinin sınanması konusunda, yaş açısından BOBİ FRS hakkındaki farkındalık düzeyleri gruplar arasındaki farklılıklar, "varyans testi" ile 
ortaya konulmaya çalışılmıştır. Sınama sonuçları Tablo 7'de verildiği gibidir.

Tablo 7. Çalışılan Bölge - Farkındalık Durumlarna Yönelik Varyans Testi Özet Tablosu

\begin{tabular}{|c|c|c|c|c|}
\hline Bölgeler & $\mathbf{N}$ & Ortalama & $F$ & $\mathbf{P}$ \\
\hline Marmara & 25 & 3,74 & \multirow{7}{*}{2,589} & \multirow{7}{*}{0,022} \\
\hline Ege & 5 & 3,42 & & \\
\hline Akdeniz & 14 & 3,73 & & \\
\hline İç Anadolu & 27 & 3,35 & & \\
\hline Karadeniz & 22 & 3,68 & & \\
\hline Doğu Anadolu & 16 & 3,52 & & \\
\hline GD Anadolu & 9 & 2,94 & & \\
\hline
\end{tabular}

Yapılan varyans testi test sonucu $\% 5$ anlamlllık düzeyi $(0,022<0,05)$ için $\mathrm{H}_{4}$ hipotezi kabul edilmiştir. Buna göre akademisyenlerin çalıştıkları bölgeler ile BOBİ FRS farkındalığı arasında anlamlı bir fark vardır. Ortalamalara dikkat edildiğinde Marmara Bölgesi akademisyenlerinin en yüksek, Güney Doğu Anadolu Bölgesi akademisyenlerinin ise en az ortalamaya sahip oldukları görülmektedir. Bunun sebebi olarak da Marmara bölgesi akademisyenlerinin daha fazla bilgiye ulaşma imkânlarının olmasından kaynaklandığı düşünülmektedir.

\section{H5: Akademisyenlerin Ders Saatleri ile BOBİ FRS Farkındalıklarn Ara- sinda Anlamlı Bir Fark Vardır}

$\mathrm{H}_{5}$ hipotezinin sınanması konusunda, yaş açısından BOBİ FRS hakkındaki farkındalık düzeyleri gruplar arasındaki farklılıklar, "varyans testi" ile ortaya konulmaya çalışılmıştır. Sınama sonuçları Tablo 8'de verildiği gibidir.

Tablo 8. Ders Saatleri-Farkındalık Durumlarına Yönelik Varyans Testi Özet Tablosu

\begin{tabular}{lllll}
\hline Ders Saatleri & $\mathbf{N}$ & Ortalama & F & P \\
\cline { 1 - 3 } 10 ve altı & 44 & 3,55 & & \\
\cline { 1 - 2 } $11-20$ & 34 & 3,54 & 0,033 & 0,992 \\
\cline { 1 - 2 } $21-30$ & 29 & 3,52 & \\
\hline 31 ve üstü & 11 & 3,49 & & \\
\hline
\end{tabular}


Yapılan varyans testi test sonucu \%5 anlamlılık düzeyi $(0,992>0,05)$ için $\mathrm{H}_{5}$ hipotezi reddedilmiştir. Buna göre akademisyenlerin yaşları ve BOBİ FRS farkındalığı arasında anlamlı bir fark yoktur.

H6: Akademisyenlerin Unvanlarn ile BOBİ FRS Farkındalıklarn Arasında Anlamlı Bir Fark Vardır

$\mathrm{H}_{6}$ hipotezinin sınanması konusunda, yaş açısından BOBİ FRS hakkındaki farkındalık düzeyleri gruplar arasındaki farklılıklar, "varyans testi" ile ortaya konulmaya çalışılmıştır. Sınama sonuçları Tablo 9'da verildiği gibidir.

Tablo 9. Unvan - Farkındalık Durumlarına Yönelik Varyans Testi Özet Tablosu

\begin{tabular}{|c|c|c|c|c|}
\hline Unvan & $\mathbf{N}$ & Ortalama & $F$ & $\mathbf{P}$ \\
\hline Prof. Dr. & 16 & 3,72 & \multirow{5}{*}{0,671} & \multirow{5}{*}{0,614} \\
\hline Doç. Dr. & 24 & 3,60 & & \\
\hline Dr. Öğr. Üyesi & 43 & 3,51 & & \\
\hline Arş. Gör. & 32 & 3,41 & & \\
\hline Öğr. Gör. & 3 & 3,61 & & \\
\hline
\end{tabular}

Yapılan varyans testi test sonucu \%5 anlamlılık düzeyi $(0,614>0,05)$ için $\mathrm{H}_{6}$ hipotezi reddedilmiştir. Buna göre akademisyenlerin yaşları ve BOBİ FRS farkındalığı arasında anlamlı bir fark yoktur.

\section{H7: Akademisyenlerin TMS/TFRS ile İlgili Ders Vermeleri ile BOBİ FRS} Farkındalıkları Arasında Anlamlı Bir Fark Vardır

$\mathrm{H}_{7}$ hipotezinin sınanması konusunda, TMS/TFRS ile ilgili ders verme açısından BOBİ FRS hakkındaki farkındalık düzeyleri gruplar arasındaki farklılıklar, "bağımsız gruplar t testi" ile ortaya konulmaya çalışılmıştır. Sınama sonuçları Tablo $10^{\prime}$ da verildiği gibidir.

Tablo 10. TMS/TFRS Ders Verme - Farkindalık Durumlarna Yönelik t Testi Özet Tablosu

\begin{tabular}{lllll}
\hline $\begin{array}{l}\text { TMS/TFRS } \\
\text { Ders Verme }\end{array}$ & $\mathbf{N}$ & Ortalama & $\mathbf{t}$ & $\mathbf{P}$ \\
\hline Evet & 49 & 3,68 & 1,985 & 0,049 \\
Hayir & 69 & 3,43 & & \\
\hline
\end{tabular}


Yapılan $\mathrm{t}$ testi test sonucu $\% 5$ anlamlılık düzeyi $(0,049<0,05)$ için $\mathrm{H} 7 \mathrm{hi}-$ potezi kabul edilmiştir. Buna göre TMS/TFRS dersleri vermek ile BOBİ FRS farkındalığı arasında anlamlı bir fark vardır. Ortalamalar açısından bakıldığında TMS/TFRS ile ilgili ders verenlerin ders vermeyenlere oranla daha yüksek değerlere sahip oldukları görülmektedir. BOBİ FRS konularını, TMS/TFRS konularıyla bağlantılı olması nedeniyle ilgili dersi veren akademisyenlerin konuyla ilgili daha ilgili oldukları ifade edilebilir.

\section{Sonuç}

Küreselleşme birçok alanı olduğu gibi muhasebe alanını da etkilemiştir. $\mathrm{Bu}$ etkilerden birisi de kullanılan muhasebe ve raporlama sistemlerinin birbiriyle uyumlu hale getirilmesi meselesidir. Bu uyum ise tek bir standardın, tüm ülkelerde aynı şekilde uygulanmasıyla sağlanabilecektir. Böylece dünyanın farklı ülkelerinde faaliyet gösteren şirketler şeffaf ve etkin finansal tablolar vasıtasıyla karşılaştırılabilecektir.

Bu hususların karşılanması açısından yapılan çalışmalardan en önemlilerinden birisi UFRS'dir. UFRS'lerin tarihi gelişimine bakıldığında, 70'li yıllardan itibaren gelişim gösterdiği, 21. yy.'la birlikte bu gelişimin meyvelerinin toplandığ görülmektedir. UFRS'nin günümüz itibariyle geldiği noktaya bakıldığında oldukça mühim ilerlemeler görülmektedir.

1 Ocak 2018 itibaren uygulanacak olan BOBİ FRS'nin uygulanması ise Türkiye'de muhasebe ve finansal raporlama açısından önemli bir gelişmedir. Türkiye'nin bu çalışmalarla hem küresel ekonominin oluşturduğu ortak muhasebe ve finansal raporlama siteminin bir parçası olma yolunda ilerlemelere katkı sağlayacaktır. Bu çalışmada da muhasebe ve finans alanında eğitim veren akademisyenlerin BOBI FRS hakkındaki farkındalıklarının ölçülmesi amaçlanmıştır. Yapılan anket sonuncunda akademisyenlerin BOBİ FRS bakış açıları ve birtakım özellikleri ile BOBİ FRS farkındalıkları arasında bir farklılık olup olmadı̆̆ı araştırılmıştır.

Yapılan araştırma sonucunda akademisyenlerin;

- BOBİ FRS, TMS/TFRS'lerin daha net anlaşılması ve doğru kullanılmalarına da katkı sağlayacağını,

- BOBİ FRS'nin iş dünyasının ihtiyaçları için gerekli olduğuna inandikları, 
- BOBİ FRS'ye göre hazırlanan finansal tabloların ülkede tek tip finansal tablo uygulamalarını yaygınlaştıracağını düşündükleri görülmektedir.

Ayrıca cinsiyet, yaş, tecrübe süresi, haftalık ders verme süreleri ve unvanları ile BOBI FRS farkındalıkları arasında anlamlı bir farklılık bulunamamıştır.

Akademisyenlerin çalıştıkları bölgeler ve TMS/TFRS ile ilgili ders vermeleri ile BOBİ FRS farkındalıkları arasında anlamlı farklılık olduğu saptanmıştır. Bu farkındalıklar arasında ise en fazla ortalamaya Marmara Bölgesi akademisyenleri ile TMS/TFRS ile ilgili bir ders vermiş akademisyenlerin sahip oldukları görülmüştür. Bunların sebebi olarak ise Marmara Bölgesi akademisyenlerinin daha fazla olanaklara sahip olmaları neticesinde daha fazla yenilikleri takip etmeleri, TMS/TFRS konularının BOBI FRS konularıyla ilişkili olması neticesinde ilgili dersi veren akademisyenlerin konuyla daha ilgili oldukları ifade edilebilir. 


\title{
EXTENDED ABSTRACT
}

\section{A Research on Academicians' Awareness of The Financial Reporting Standard For Large and Medium-Sized Businesses}

\author{
Murat Serçemeli - Muammer Paça \\ *
}

Giresun University

The effects of rapid development and globalization in the world economies have lifted the borders between countries and greatly improved the scope of trade and investment between each other. Now, an investor wants to be able to make different investments by looking at different countries, not only in his own country but also in different countries of the world.

The increase in international trade and competition, the conclusion of international agreements and the rapid development of technology have started globalization and the effect of globalization has increased gradually in recent years. The impact of globalization has affected and changed the economy as well as all other fields. This change, which emerged as a result of globalization in the field of economy, necessitated changes in accounting. While each country is using a different accounting system suitable for itself, it is necessary to switch to a common accounting system (Güneş et al., 2012, s.57).

The most important source for the investors who want to establish a partnership with the enterprises and to invest in the stocks and institutions that give credit is the financial statements of that company. The fact that companies operating in different countries have their own accounting and reporting system makes it difficult to compare and analyze them transparently and effectively. This difficulty can be solved by common accounting and financial reporting in all countries.

Now, the increase in the number of enterprises engaged in cross-border activities, market developments, capital movements accelerated the formation of a common financial reporting system. Investors make international investments and know no limits. A common financial reporting is 
needed to understand and compare the financial situation of the countries and businesses to be invested. Each country has its own reporting system, but it is difficult to compare them because each country has different legislation and practices. As a result of the globalization movement, standardization of accounting and financial reporting procedures was made and a common accounting language was requested (Kocamaz, 2012: 106). Thus, the differences between the countries have been reduced or eliminated, easily comparable, easy to understand information about the financial situation was tried to be obtained.

The enterprises that will implement BOBİ FRS are defined as follows. "Total assets of TL 75 million and above, annual net sales revenue of TL 150 million and above, with an average number of employees of 250 and above are defined as enterprises. Enterprises exceeding the threshold values of at least two of these three criteria together with their subsidiaries, if any, are considered as large enterprises in the subsequent reporting period "(30138, Official Gazette).

Depending on developments in the fields of accounting and finance changes in the financial reporting system in Turkey is experiencing. With these changes, new reporting systems affect academicians in accounting and accounting finance. Previously issued by the Public Oversight Authority (TFRS) in order to ensure compliance with the international financial reporting system, then in 2018, the BOB FRS was published. The purpose of this study is measure the awareness of the academicians about to be implemented from 1 January 2018, the Financial Reporting Standard for Large and Medium Businesses published by the Public Oversight Agency and to determine whether there is any difference between the academicians' awareness.

For this purpose, a survey was conducted among the academicians working in the field of accounting and finance. According to the results of the study, it was seen the academicians believes that BOBI FRS will contribute to a better understanding and correct use of the TMS / TFRS, it is necessary for the needs the business world and that the financial statements prepared according to BOBI FRS will spread the uniform financial statements in the country. In addition, it was determined that there was a significant difference BOBI FRS awareness between academicians' working regions and giving lessons about TMS / TFRS. 
It was found that there was a significant difference between the academicians' working areas and TMS / TFRS lectures and BOBI FRS awareness. Among these awareness, it was seen that Marmara Region academicians and academicians who gave a course on TMS / TFRS had the highest average. As a result of this, it can be stated that the academicians who teach the related course are more interested in the fact that the Marmara Region academicians follow more innovations as they have more opportunities and TMS / TFRS issues are related to BOBI FRS subjects.

\section{Kaynakça / References}

Ataman, B. ve Cavlak, H. (2017). Büyük ve orta boy işletmeler için finansal raporlama standardı (BOBI FRS) ile tam set türkiye muhasebe ve Türkiye finansal raporlama standartlarının (tms/tfrs) karşılaştırılması. Finans Ekonomi ve Sosyal Araştırmalar Dergisi, 2(3), 153-168.

Ataman, B., Gökçen, G. ve Cavlak, H. (2018). Muhasebe sistemi uygulama genel tebliği'ne (MSUGT'ye) göre hazırlanan finansal tabloların büyük ve orta boy işletmeler için finansal raporlama standardı'na (BOBİ FRS'ye) uyarlanması ve rasyo yöntemi ile analizi. Finans Ekonomi ve Sosyal Araştırmalar Dergisi, 3(2), 458-477.

Bayram, N. (2017). Sosyal bilimlerde SPSS ile veri analizi. Bursa: Ezgi Kitabevi

Doğan, A. (2017). Büyük ve orta boy işletmeler için finansal raporlama standardı ile TMS/TFRS karşılaştırması. İşletme Araştırmaları Dergisi, 9(4), 770-786.

Gençoğlu, G. Ü. (2017). Temel konularda BOBİ FRS ve TMS/TFRS karşılaştırması. Muhasebe ve Finansman Dergisi, 76, 1-24.

Gökçen, G., Öztürk, E. ve Güleç, Ö.F. (2018). BOBİ FRS ve TFRS'nin finansal raporlara etkileri açısından karşılaştırılması. Finans Ekonomi ve Sosyal Araştırmalar Dergisi, 3(2), 437-457.

Güneş, R., Durmuş, A.F. ve Solak, B. (2012). Küreselleşmenin muhasebe uygulamalarına etkisi. Akademik Yaklaşımlar Dergisi, 3(2), 57-66.

Kalayc1, Ş. (2010). SPSS uygulamal çok değişkenli istatistik teknikleri. (5. Bs) Ankara: Asil Yayınları, 
Kamu Gözetimi Kurumu (2017). Büyük ve orta boy işletmeler için finansal raporlama standardl. 24.12.2017 tarihinde http://www.kgk.gov.tr/ContentAssingmentDetail/1349/BüyukveOrtaBoyIssletmelerIçinFinansal-Raporlama-Standard1-ResmiGazetede-Yayımlandı adresinden erişilmiştir.

Kaya, U. ve Dinç, E. (2007). Türkiye muhasebe standartlarına göre maddi duran varlıkların değerlenmesi ve muhasebeleştirilmesi. Çukurova Üniversitesi Sosyal Bilimler Enstitüsü Dergisi, 16(2), 343-364.

Kocamaz, H. (2012). Uluslararası muhasebe standartlarının dünyada ve türkiye'de oluşum ve gelişim süreci. Kahramanmaraş Sütçü İmam Üniversitesi İIBF Dergisi, 2(2), 105-120.

Mozeikçi, A.A. ve Şahinoğlu, K.T. (2018). BOBİ FRS' nin getirdiği değişikliklerin uygulayıcılar tarafından algılanma düzeyi: Kırklareli İlinde bir araştırma. Kırklareli Üniversitesi İktisadi ve İdari Bilimler Fakültesi Dergisi, 7(2), 38-49.

Öztürk, E. (2017). Finansal varlıkların ölçme ve muhasebeleştirme esaslarının büyük ve orta boy işletmeler için finansal raporlama standardı ve türkiye finansal raporlama standartları açısından karşılaştırılması. İşletme Araştırmaları Dergisi, 9(3), 594-617.

Öztürk, M.S. ve Çarıkçı, O. (2018). Büyük ve orta boy işletmeler için finansal raporlama standardının muhasebe meslek mensupları üzerinde algı düzeyinin araştırılması. Mehmet Akif Ersoy Üniversitesi İktisadi ve İdari Bilimler Dergisi, 5(3), 568-582.

Büyük ve Orta Boy İşletmeler için Finansal Raporlama Standardı Hakkında Tebliğ. (Temmuz 29, 2017). Resmi Gazete. (Sayı:30138 (Mükerrer))

Sakarya, Ş., Yazgan, K.F. ve Yıldırım, H.H. (2018). Büyük ve orta boy işletmeler için finansal raporlama standardı (BOBİ FRS)'nın muhasebe meslek mensupları tarafından bilinirliğinin ve farkındalığının tespiti: Balıkesir İli örneği. Muhasebe ve Vergi Uygulamaları Dergisi, Nisan (Özel Sayı), 699-724.

Şen, İ.K ve Özbirecikli, M. (2018). BOBİ FRS'nin muhasebe uygulamalarına getirdiği değişiklikler: BOBİ FRS, TMS/TFRS ve mevcut muhasebe sistemi çerçevesinde bir inceleme. Muhasebe ve Vergi Uygulamaları Dergisi, Nisan (Özel Sayı), 462-484. 
Yılmaz, Z., Şahin, Z. ve Çankaya F. (2014). Orta ve Doğu Karadeniz Bölgesindeki öğrenci, akademisyen ve uygulayıcıların TMS/TFRS farkındalık ve görüşleri üzerine bir çalışma. Muhasebe Bilim Dünyası Dergisi, 16(2), 109-135.

\section{Kaynakça Bilgisi / Citation Information}

Serçemeli, M. ve Paça, M. (2019). Büyük ve orta boy işletmeler için finansal raporlama standardı ile ilgili akademisyenlerin farkındalıkları hakkında araştırma. OPUS-Uluslararası Toplum Araştırmaları Dergisi, 12( 18. UIKK Özel Sayıs1), 14-36. DOI: 10.26466/opus.583677 